\title{
Immediate Release of Gastrin-Releasing Peptide Mediates Delayed Radiation-Induced Pulmonary Fibrosis
}

Robert M. Tighe, ${ }^{*}$ Karissa Heck, ${ }^{\dagger}$ Erik Soderblom, ${ }^{\ddagger}$ Shutang Zhou ${ }^{\dagger}$ Anastasiya Birukova, ${ }^{*}$ Kenneth Young, ${ }^{\S}$ Douglas Rouse, ${ }^{\top}$ Jessica Vidas, ${ }^{\dagger}$ Miglena K. Komforti, ${ }^{\dagger}$ Christopher B. Toomey, ${ }^{\dagger}$ Frank Cuttitta, ${ }^{\|}$and Mary E. Sunday ${ }^{\star \dagger}$

From the Division of Pulmonary-Critical Care, ${ }^{*}$ Department of Medicine, the Departments of Pathology, ${ }^{\dagger}$ Cell Biology, ${ }^{\ddagger}$ and Radiation Oncology, ${ }^{\S}$ and the Division of Laboratory Animal Resources, "Duke University Durham, North Carolina; and the Mouse, Cancer and Genetics Program, ${ }^{\|}$National Cancer Institute, Frederick, Maryland

\author{
Accepted for publication \\ January $31,2019$. \\ Address correspondence to \\ Mary E. Sunday, M.D., Ph.D., \\ Duke University Medical Cen- \\ ter, 40 Duke Medicine Cir. \\ Davison Bldg., Room 204, \\ Durham, NC 27710. E-mail: \\ mary.sunday@duke.edu.
}

\begin{abstract}
Radiation-induced pulmonary fibrosis (RTPF) is a progressive, serious condition in many subjects treated for thoracic malignancies or after accidental nuclear exposure. No biomarker exists for identifying the irradiated subjects most susceptible to pulmonary fibrosis (PF). Previously, we determined that gastrinreleasing peptide (GRP) was elevated within days after birth in newborns exposed to hyperoxia who later developed chronic lung disease. The goal of the current study was to test whether radiation (RT) exposure triggers GRP release in mice and whether this contributes to RTPF in vivo. We determined urine GRP levels and lung GRP immunostaining in mice 0 to 24 after post-thoracic RT (15 Gy). Urine GRP levels were significantly elevated between 24 hours post-RT; GRP-blocking monoclonal antibody 2A11, given minutes post-RT, abrogated urine GRP levels by 6 to 12 hours and also altered phosphoprotein signaling pathways at 24 hours post-RT. Strong extracellular GRP immunostaining was observed in lung at 6 hours post-RT. Mice given one dose of GRP monoclonal antibody 2A11 24 hours post-RT had significantly reduced myofibroblast accumulation and collagen deposition 15 weeks later, indicating protection against lung fibrosis. Therefore, elevation of urine GRP could be predictive of RTPF development. In addition, transient GRP blockade could mitigate PF in normal lung after therapeutic or accidental RT exposure. (Am J Pathol 2019, 189: 1029-1040; https://doi.org/10.1016/j.ajpath.2019.01.017)
\end{abstract}

Pulmonary fibrosis (PF) can be a delayed sequela of either therapeutic or accidental exposure to radiation (RT). ${ }^{1}$ Inflammatory radiation-induced pneumonitis (RTP) develops approximately 1 to 6 months post-RT in approximately $5 \%$ to $15 \%$ of lung cancer patients (approximately 20,000 of lung cancer patients per year in the United States), with risk factors including preexisting chronic lung disease, higher radiation doses, and the size of the exposure field. ${ }^{2}$ Many of these RTP patients later develop radiation-induced $\mathrm{PF}$ (RTPF). ${ }^{3}$ The mechanism(s) underlying the early RTP leading to RTPF remain(s) poorly understood, and presently, there are no mechanistic biomarkers to identify individuals at greatest risk for developing RTPF. $^{3}$ Such markers would be critical to enable prediction of these responses and to consider therapeutic modalities.
In a previous study, we showed that RTPF could be significantly reduced by gastrin-releasing peptide (GRP) blockade injected twice weekly from 1 hour post-RT up until 20 weeks later. ${ }^{4}$ These experiments were designed to test the hypothesis that blockade of GRP at any time postRT could alter later RTPF in fibrosis-prone C57BL/6 mice. RTPF was demonstrated at 20 weeks post-RT by immunostaining for $\alpha$-smooth muscle actin ( $\alpha$-SMA), a myofibroblast marker in alveoli, and Masson's trichrome

Supported by NIH grant K08-HL105537 (R.M.T.); the Department of Pathology, Duke University (K.H. and M.E.S.); and the Jenny Lillian Semans Koortbojian Trust Fund, Charlotte, NC (M.E.S.).

R.M.T. and K.H. contributed equally to this work.

Disclosures: None declared. 
(TRI) staining for collagen. ${ }^{4}$ At that time, we had no knowledge about when GRP might promote fibrosis.

In the present study, we now test the hypothesis that radiation induces early and rapid GRP secretion by pulmonary neuroendocrine (NE) cells (PNECs), and this could predict the development of RTPF. We now use an established $\mathrm{C} 57 \mathrm{~L} / \mathrm{J}(\mathrm{L} / \mathrm{J})$ mouse model of RTPF to investigate early mechanisms preceding RTPF because L/J mice have radiation sensitivity similar to humans and do not develop pleural effusions. ${ }^{5}$ In contrast, C57BL/6 mice are fibrosis prone, but unlike humans, they develop lethal pleural effusions. ${ }^{5-7}$ Using lung immunostaining and urine enzyme immunoassay (EIA) for GRP, we detected GRP during the first 0 to 24 hours post-RT. To determine whether this early expression of GRP mediates RTPF, we treated a cohort of RT-exposed mice with one dose of the GRP-neutralizing monoclonal antibody (mAb) 2A11 (RT $+2 \mathrm{~A} 11)$ versus $\mathrm{RT}+$ phosphate-buffered saline (PBS) at 24 hours post-RT. This later timing for therapeutic efficacy of a radiation-mitigating agent is required by the NIH (Bethesda, MD) RadCCOR Program. We observed that this single injection of mAb $2 \mathrm{~A} 11$ at 24 hours post-RT abrogates the development of RTPF progression at 15 weeks post-RT.

To explore GRP-related molecular signaling pathways regulating RTPF, we performed proteomics and phosphoproteomics of lung tissue at 24 hours post-RT \pm mAb $2 \mathrm{~A} 11$ and identified potential early phosphorylation of GRPrelated molecular signatures at 24 hours post-RT. These data indicate that GRP can be released within hours postRT. Moreover, this early release regulates later development of RTPF, likely via early changes in phosphorylation of GRP protein targets. This has implications for diagnosis and treatment of RTPF.

\section{Materials and Methods}

\section{Mice}

L/J mouse breeder pairs were purchased from Jackson Laboratories (Bar Harbor, ME) and then bred at Duke University (Durham, NC). All experiments were approved by the Duke Institutional Animal Care and Use Committee and followed the guidelines of the NIH Guide for the Care and Use of Laboratory Animals. ${ }^{8}$ Female L/J mice, at 8 to 12 weeks of age, were exposed to $15 \mathrm{~Gy}$ of thoracic radiation using a custom-designed small animal platform ${ }^{9}$ and harvested for outcomes at 24 hours or 15 weeks post-RT. ${ }^{4}$ At 1 or 24 hours post-RT, a subset of mice was injected intraperitoneally with a low endotoxin and azidefree GRP-neutralizing mouse mAb 2A11 $(5 \mu \mathrm{g} / \mathrm{kg}$ intraperitoneally; kindly provided by F.C.). Urine was obtained and lungs were harvested at 24 hours or 15 weeks postRT. Before harvest, mice were euthanized by $\mathrm{CO}_{2}$ asphyxiation.

\section{Urine Collections and GRP EIA}

Urine was collected for 6 hours by placing the mice in metabolic cages (model MMC100; Hatteras, Cary, NC). After collection, urine was stored at $-80^{\circ} \mathrm{C}$ until assayed. The identity of the urine samples was coded so that the individual performing the assays had no knowledge of either the mouse or time of origin. For the GRP EIA, we treated urine samples with acetic acid (1N) and heated them to $95^{\circ} \mathrm{C}$ for 5 minutes to aggregate binding proteins, which precipitated and then were separated by centrifugation. GRP was assayed in supernatants using a standardized human GRP EIA kit, 100\% specific for both human and mouse GRP (Phoenix Pharmaceuticals, Burlingame, CA), as previously described. ${ }^{10}$ Results were normalized for creatinine assayed using nonacidified urine samples with a commercially available kit (Cayman Chemicals, Ann Arbor, MI).

\section{Immunohistochemistry}

\section{Antibodies}

Lung tissues were stained using an mAb 2A11, anti-protein-gene product 9.5 (PGP 9.5), and anti- $\alpha$-SMA. mAb 2A11 was diluted 1:100 in 1\% bovine serum albumin/ PBS (final, $10 \mu \mathrm{g} / \mathrm{mL}$ ). Rabbit polyclonal anti-PGP 9.5, obtained from Gene Technology Co, Ltd (Shanghai, China), was used at 1:500 dilution. Murine monoclonal anti- $\alpha$ SMA (clone 1A4) conjugated with alkaline phosphatase, purchased from Sigma-Aldrich (St. Louis, MO), was used at a 1:60 dilution.

\section{Absorption of mAb 2A11 with Solid-Phase GRP}

Polystyrene tubes were coated with either $1 \%$ bovine serum albumin/PBS or GRP in $1 \%$ bovine serum albumin/PBS (10 $\mu \mathrm{g} / \mathrm{mL}$; Anaspec, Freemont, CA) for 1 hour at $4^{\circ} \mathrm{C}$ on a tube rotator. After washing with $1 \%$ bovine serum albumin/PBS and then PBS, we added mAb 2A11 $(10 \mu \mathrm{g} / \mathrm{mL})$ and rotated tubes overnight at $4^{\circ} \mathrm{C}$. Supernatants were used for immunohistochemistry (IHC).

\section{IHC}

We performed immunostaining for the mature GRP peptide (a PNEC neurosecretory granule marker) and PGP 9.5 (the neural/ NE cytoplasmic isoform of ubiquitin-C-terminal hydrolase 1), as described previously. ${ }^{4}$ For GRP and PGP 9.5 IHC, formalinfixed, paraffin-embedded lung sections were treated for $10 \mathrm{mi}-$ nutes with Triton X-100 (0.3\% in PBS; Sigma-Aldrich, Raleigh, $\mathrm{NC}$ ), and then normal serum blocking was performed, as described. ${ }^{4}$ Diluted primary antibodies were added to sections overnight at $4^{\circ} \mathrm{C}$, followed by washing in PBS and 2 hours at $4^{\circ} \mathrm{C}$ with a 1:200 dilution of biotinylated secondary antibodies (Vector, Burlingame, CA). After blocking in $3 \% \mathrm{H}_{2} \mathrm{O}_{2}$ in methanol, Vector ABC Elite was applied to slides for $30 \mathrm{mi}-$ nutes. Slides were developed by using diaminobenzidine and hydrogen peroxide, then counterstained in $2 \%$ aqueous methyl green. For $\alpha$-SMA IHC, sections were pretreated with Triton X100 , followed by $1: 60$ anti- $\alpha$-SMA mAb conjugated with 
alkaline phosphatase incubated at $4^{\circ} \mathrm{C}$ overnight. After washing, slides were developed with Vector Impact Red and counterstained with methyl green. Trichrome staining was performed by standard methods at the Duke Histopathology Research Core Laboratory by using light green for staining collagen.

\section{ImageJ Analysis}

All slides were blinded for ImageJ version 1.62 (NIH; http:// imagej.nih.gov/ij) analysis before one pathologist (M.K.K.) took random photomicrographs with a Nikon Eclipse E600 digital camera (Nikon Corporation, Melville, NY), using ActI software version 1.0 (Nikon Corporation). Thresholding parameters were determined by one student (C.B.T.) using positive control slides, as follows: i) Red indicates $\alpha$-SMA specific: hue, 225 to 255 ; saturation, 50 to 255 ; brightness, 0 to 200; analyze particles at 15 to $1500 \mu \mathrm{m}$; ii) Green indicates methyl green nuclear counterstain: hue, 50 to 150; saturation, 45 to 255 ; brightness, 0 to 200; analyze particles at 15 to $1500 \mu \mathrm{m}$; iii) TRI indicates green for collagen: hue, 50 to 150 ; saturation, 45 to 255 ; brightness, 0 to 200; analyze particles at 15 to 1500 $\mu \mathrm{m}$; and iv) Purple indicates hematoxylin nuclear counterstain for the total tissue area in trichrome-stained slides (minus erythrocytes): hue (all pass), 15 to 217; saturation, 5 to 255 ; brightness, 0 to 193; analyze particles at 15 to $1500 \mu \mathrm{m}$.

ImageJ analysis was performed by a different pathology student (K.H.). Results are expressed as mean percentage of tissue area positive for $\alpha$-SMA or TRI in 10 to 20 nonoverlapping photomicrographs of alveoli per mouse, all lobes included, taken at $40 \times$ magnification. These data were normalized for the volume of tissue, as represented by the nuclear counterstains, methyl green or hematoxylin. Final results were validated qualitatively on blinded slides by another pathologist (M.E.S.).

\section{Lung Cytokine Assay}

Cytokines in the right middle lobe of the lung were assayed with the Beadlyte Milliplex Mouse 20-plex immunoassay by following manufacturer's protocols (Millipore-Aldrich, St. Louis, MO), which included the following cytokines: granulocyte-macrophage colony-stimulating factor, interferon- $\gamma$, IL-1 $\alpha$, IL-1 $\beta$, IL-2, IL-4, IL-5, IL-6, IL-10, IL-12p40, IL-12p70, IL-13, IL-17, keratinocyte chemoattractant (KC, alias murine IL-8), macrophage inflammatory protein (MIP)-1a, monokine induced by $\gamma$-interferon (MIG, alias CXCL9), chemokine (C-C motif) ligand 2, vascular endothelial growth factor, and tumor necrosis factor- $\alpha$.

\section{Differential Phosphopeptide Expression Analysis by Liquid Chromatography-Tandem Mass Spectrometry}

We provided the Duke Phosphoproteomics Core Laboratory with 10 frozen whole lungs for phosphopeptide analysis, which was performed as previously described. ${ }^{11}$

\section{Statistical Analysis}

Statistical analysis was performed by using the one-way $t$-test, with significance defined as $P<0.05$ or $P<0.01$, as defined in Results. Statistical analyses were performed using the one-way $t$-test to compare two groups.

\section{Results}

\section{Urine Levels of GRP Are Increased after RT Exposure}

$\mathrm{L} / \mathrm{J}$ mice exposed to $15 \mathrm{~Gy}$ thoracic radiation were injected with $\mathrm{mAb} 2 \mathrm{~A} 11(5 \mu \mathrm{g} / \mathrm{kg}), 10$ minutes post-RT, or vehicle control (PBS), as soon as they recovered from anesthesia (Figure 1A), and then placed in metabolic cages. Urine was collected for 6-hour intervals ( 0 to 6, 6 to 12,12 to 18 , and 18 to 24 hours) for GRP EIA, which was normalized for creatinine (pmol/mg creatinine). Results were compared with 6-hour urine specimens collected from the same mice on the day before radiation (pre-RT).

Within each experiment, we observed no significant difference in baseline GRP levels before radiation (means \pm SEM pre-RT pooled absolute values: experiment $1,138 \pm 30 \mathrm{pg} / \mathrm{mg}$ creatinine; experiment $2,197 \pm 60 \mathrm{pg}$ $\mathrm{GRP} / \mathrm{mg}$ creatinine). Means \pm SEM pre-RT urine GRP levels at different time intervals were $161 \pm 23 \mathrm{pg} \mathrm{GRP} / \mathrm{mg}$ creatinine at 0 to 6 hours, $89 \pm 27 \mathrm{pg} \mathrm{GRP} / \mathrm{mg}$ creatinine at 6 to 12 hours, $65 \pm 26 \mathrm{pg} \mathrm{GRP} / \mathrm{mg}$ creatinine at 12 to 18 hours, and $103 \pm 24 \mathrm{pg} \mathrm{GRP} / \mathrm{mg}$ creatinine at 18 to 24 hours. We used the one-way $t$-test to compare pre-RT urine GRP values with urine GRP levels from sham (no RT) mice at subsequent time intervals: pre-RT pool versus 0 - to 6-hour sham control was 0.46 , pre-RT pool versus 6- to 12-hour sham control was 0.41 , pre-RT pool versus 12 - to 18 -hour sham control was 0.35 , and pre-RT pool versus 18 to 24-hour sham control was 0.46. Comparison of all pre-RT urine GRP values from experiment 1 versus experiment 2 yielded a $P=0.35$. Experiment 3 had a higher absolute baseline pre-RT value ( $525 \pm 50 \mathrm{pg}$ GRP/mg Cr), which could be due to using a fresh GRP EIA kit. Regardless, when post-RT values from experiment 3 were normalized for this baseline, patterns of elevated urine GRP at different time intervals were similar to experiments 1 and 2.

Post-RT GRP levels were normalized to mean baseline values in each of three separate experiments (Figure 1B). Pooled GRP levels from mice exposed to RT + PBS were highest between 0 and 6 hours post-RT and subsequently declined, remaining significantly elevated over pre-RT values at 18 to 24 hours. Urine GRP levels from mice exposed to $\mathrm{RT}+\mathrm{mAb} 2 \mathrm{~A} 11$ were high at 0 to 6 hours, decreased to pre-RT values by 6 to 12 hours post-RT (Figure 1B), and then were significantly below pre-RT levels by 18 to 24 hours post-RT. When complete sets of urine samples were assessed from individual RT + PBS mice, there was variability in the precise timing of the peak 
A

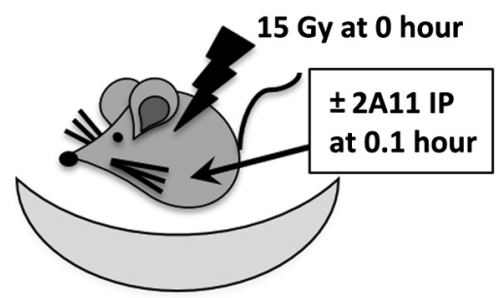

Metabolic cages: Urine

$0-6,6-12,12-18,18-24$ hours

B

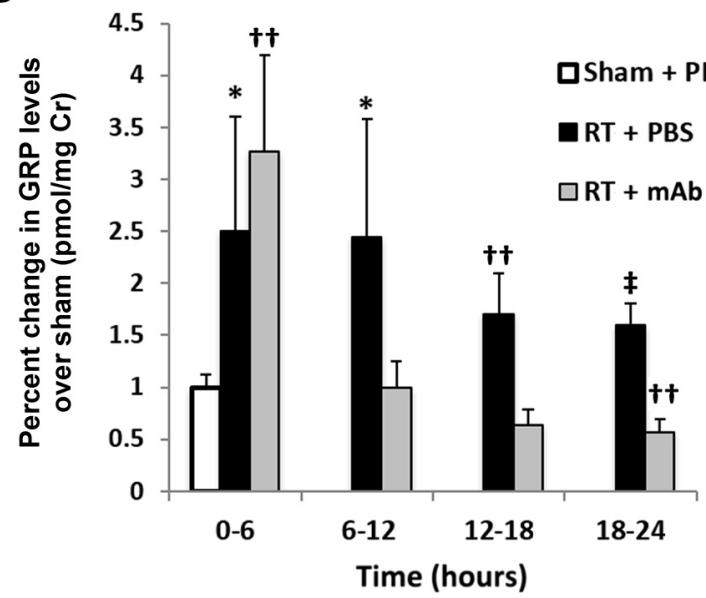

Figure 1 Elevated urine levels of gastrin-releasing peptide (GRP) from C57L/J (L/J) mice at 0 to 24 hours post-radiation (RT). L/J mice exposed to $15-G y$ thoracic radiation were given monoclonal antibody (mAb) $2 \mathrm{~A} 11$ or phosphate-buffered saline (PBS) 10 minutes post-RT (or as soon as mice recovered from anesthesia). A: Urine specimens were collected in metabolic cages for 6-hour intervals pre-RT and post-RT. GRP was measured, and levels were normalized for creatinine. B: Pooled results of GRP levels after RT were normalized for mean pre-RT baseline. $n=18$ sham + PBS (B); $n=11 \mathrm{RT}+\mathrm{PBS}(\mathrm{B}) ; n=8 \mathrm{RT}+\mathrm{mAb} 2 \mathrm{~A} 11 .{ }^{*} P<0.05$ versus pre-RT baseline; ${ }^{\dagger \dagger} P<0.01$ versus baseline; ${ }^{\ddagger} P<0.05$ RT + PBS versus baseline at 18 to 24 hours (RT + mAb 2 A11 versus RT + PBS at 18 to 24 hours; one-way $t$-tests comparing GRP levels). IP, intraperitoneally.

GRP level (Supplemental Figure S1). The pooled GRP data were reproducibly significant, even as the 18- to 24-hour post-RT + PBS level decreased to $1.5 \times$ the baseline control value.

\section{IHC for GRP and PGP 9.5}

To identify PNECs in lung tissue from RT-exposed mice, we performed IHC. GRP is a neurosecretory granule NE marker, and PGP 9.5 is an NE cytoplasmic marker. ${ }^{12}$ In nonradiated sham controls, normal-appearing NE cell clusters are strongly PGP $9.5^{+}$(Figure 2A); modest PGP $9.5^{+}$ staining is occasionally visible in some epithelial cells adjacent to PNEC clusters, consistent with early NE cell differentiation. An internal positive control was used for PGP 9.5 intrapulmonary nerve fibers. PGP $9.5^{+}$cells 6 hours post-RT (Figure 2B) appear similar to sham controls. At 24 hours post-RT, there was a trend toward increased total numbers of PGP $9.5^{+}$cells per lung area (Figure 2C). In sham controls, most NE cells were GRP negative or had modest GRP immunostaining in $\mathrm{L} / \mathrm{J}$ mice (Figure 2D). ${ }^{12}$ At 6 hours post-RT, scattered PGP $9.5^{+}$foci (Figure 2C) had modest GRP immunostaining in adjacent sections (Figure 2E). Most of the GRP immunostaining in lung postRT was in distal alveolar airspaces and venules at 6 hours (Figure 2E) and 24 hours (Figure 2, F and G) post-RT. We did not observe GRP immunostaining in conducting airways (Figure 2G). To confirm the specificity of the GRP staining, we performed negative controls by using immediately adjacent sections: Figure $2 \mathrm{H}$ to Figure $2 \mathrm{G}$ and Figure $2 \mathrm{~J}$ to Figure 2I, run in parallel with the same 1:100 dilution of mAb 2A11 preabsorbed with solid-phase GRP (Figure 2, G-J). These observations demonstrate that GRP is specifically increased at early time points in the lung after RT exposure, consistent with the data from the urine studies.

\section{GRP Blockade in Vivo}

Given the early increase in GRP after RT, we were interested in determining if suppression of this early GRP would affect RTPF development. Therefore, we blocked GRP using mAb 2A11 $(100 \mu \mathrm{g}$ intraperitoneally) at 24 hours post-RT (RT $+\mathrm{mAb}$ 2A11) (Figure 3A), compared with PBS-treated mice (RT + PBS) and nonirradiated sham controls as positive and negative controls, respectively. At 15 weeks after exposure, animals were harvested and histologic staining was performed for $\alpha$-SMA, TRI, and collagen-I (Col-I) staining (Figures 3 and 4). $\alpha$-SMA is a marker of normal smooth muscle and myofibroblasts. ${ }^{13}$ Myofibroblasts are a hallmark of early fibrosis during which pericytes localized to small peripheral blood vessels differentiate into myofibroblasts and migrate into injured tissues. Representative photomicrographs of $\alpha$-SMA IHC are given in Figure 3, B-D. Sham controls (Figure 3B) demonstrated the expected distribution in normal smooth muscle of airways and blood vessels (venules). In RT + PBS lung 15 weeks post-RT, we observed markedly increased myofibroblasts in alveolar walls (Figure 3C). In contrast, in RT + mAb 2 A11 lung 15 weeks post-RT, compared with mice exposed to RT + PBS, we observed markedly reduced $\alpha$ $\mathrm{SMA}^{+}$immunostaining in alveolar walls (Figure 3D), with most $\alpha-\mathrm{SMA}^{+}$immunostaining being restricted to airway and vascular smooth muscle (Figure 3D).

TRI is a marker of the synthetic phase of fibrosis and can represent interstitial collagen deposition in alveoli. ${ }^{14} \mathrm{Sec}$ tions of mouse lung at 15 weeks post-RT are shown in Figure 3, E-G. No interstitial collagen was observed in sham controls (Figure 3E), which had normal TRI staining in association with conducting airways and blood vessels (venules). Interstitial collagen was observed 15 weeks post$\mathrm{RT}+$ PBS (Figure 3F). This interstitial collagen was markedly reduced 15 weeks post-RT + PBS in mice treated with a single dose of $\mathrm{mAb} 2 \mathrm{~A} 11$ at 24 hours post-RT (Figure 3G).

To demonstrate that the TRI staining is collagen specific, we performed immunostaining for Col-I, the principal collagen secreted by synthetic fibroblasts, in serial sections 

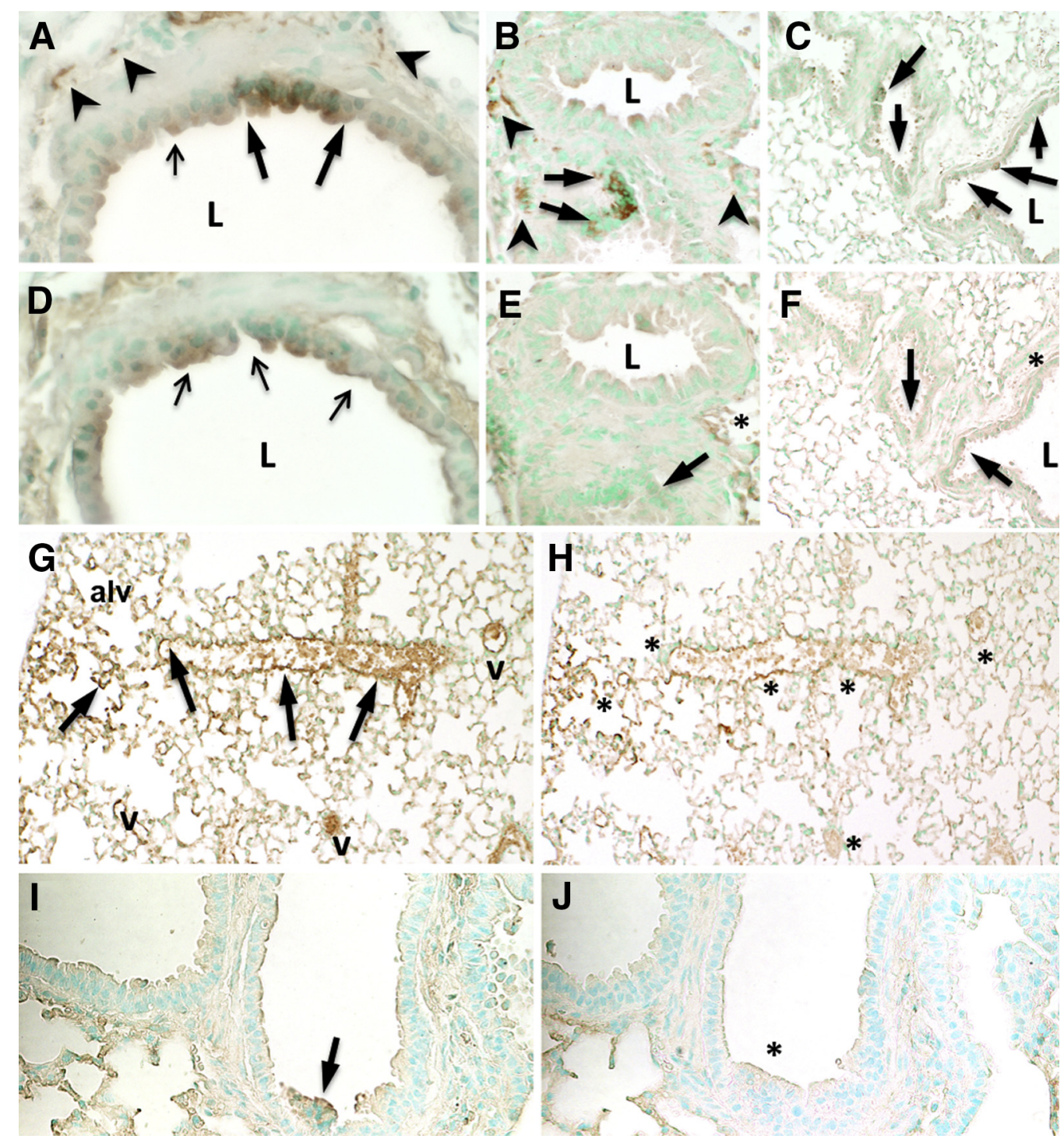

Figure 2 Immunohistochemistry for protein-gene product 9.5 (PGP 9.5) and gastrin-releasing peptide (GRP) at 0 to 24 hours post-radiation (RT). Lung tissue sections were obtained from C57L/J mice after 15-Gy thoracic radiation for PGP 9.5 and GRP immunostaining. PGP 9.5 is a neuroendocrine $(\mathrm{NE})$ /neural cytoplasmic marker for pulmonary NE cells (PNECS) and pulmonary nerve fibers. GRP is a neurosecretory granule marker that only detects PNECs. A-C: PGP 9.5. D-G and I: GRP. H and J: Anti-GRP monoclonal antibody (mAb) preabsorbed with solid-phase GRP. A and D: Pre-RT. B and E: At 6 hours post-RT. C and F: At 24 hours post-RT. $\mathbf{G}$ and $\mathbf{H}$ : At 6 hours post-RT. I and J: At 24 hours post-RT. A: Pre-RT, PGP 9.5 immunohistochemistry (IHC) shows normal-appearing NE cells in small clusters (between arrows) within the epithelium of a conducting airway. Modest PGP 9.5 staining flanks the main NE cell cluster (small arrow). Arrowheads indicate a PGP 9.5 intrapulmonary nerve fiber as an internal positive control. B: At 6 hours post-RT, PGP $9.5^{+}$cells are present in a cluster within the epithelium of a conducting airway (arrows). Note the intrapulmonary nerve fibers (arrowheads). C: At 24 hours post-RT, strongly PGP $9.5^{+}$cells occur in small clusters scattered in conducting airways (arrows). D: In sections immediately adjacent to A, there is modest GRP immunostaining parallel to the PGP $9.5^{+} \mathrm{NE}$ cells (arrows). E: A section adjacent to B shows modest GRP ${ }^{+}$immunostaining (arrow). F: Minimal GRP is detected in PNECs next to C (arrows) at 24 hours post-RT. G: At 6 hours post-RT, GRP immunostaining is specifically and strongly positive in alveolar spaces (alv) and in many post-capillary venules (v) along the endothelium (arrows). H: A lung section immediately adjacent to $\mathbf{G}$ was obtained in parallel with the same dilution of monoclonal antibody 2 A11 preabsorbed with solid-phase GRP. GRP immunostaining is markedly reduced in serial sections (asterisks). I: At 24 hours post-RT, a small cluster of GRP ${ }^{+}$PNECs is detected in a bronchiole (arrow). J: An asterisk indicates reduced GRP immunostaining by solid-phase GRP immunodepletion. Asterisks in $\mathbf{H}$ and $\mathbf{J}$ indicate reduced GRP immunostaining as compared to serial sections in $\mathbf{G}$ and $\mathbf{I}$, respectively, after solid-phase GRP immunodepletion. Original magnifications: $\times 20(\mathbf{A}, \mathbf{B}, \mathbf{D}$, and $\mathbf{E}$ and $\mathbf{G}-\mathbf{J}) ; \times 10(\mathbf{C}$ and $\mathbf{F})$. L, airway lumen.

of normal L/J lung (Figure 4B) and in mice 15 weeks after 15-Gy RT was given (Figure 4D). Image in Figure 4, A and $\mathrm{C}$, were TRI stained, and this staining aligned well with ColI immunostaining in immediately serial sections (Figure 4,
B and D). Normally, Col-1 is distributed extracellularly around bronchioles and vasculature (Figure 4, B and D). At 15 weeks post-RT (Figure 4, C and D), TRI and Col-1 staining infiltrated the alveoli, staining small nodules of 
A
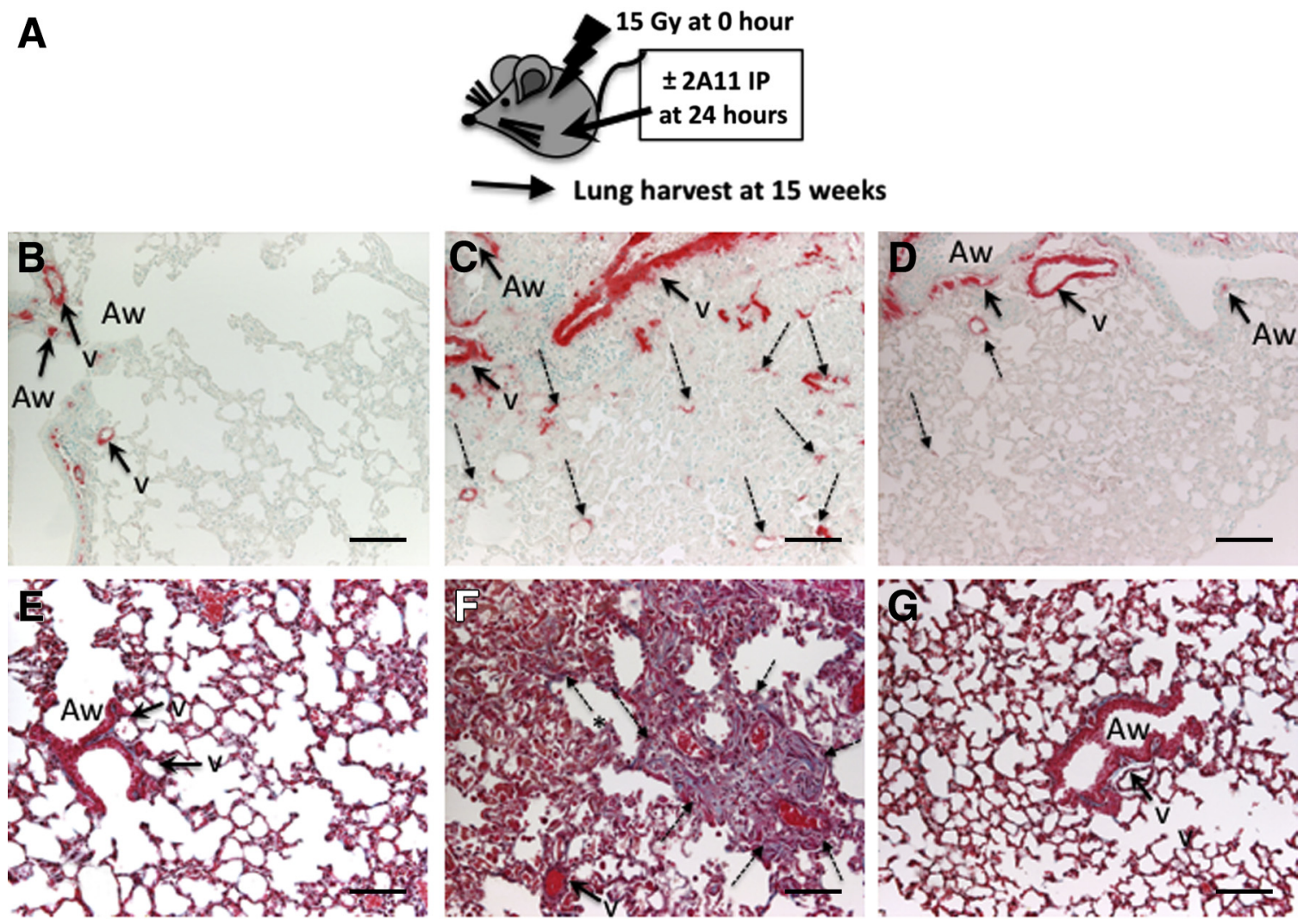

Figure 3 Staining of lung sections for $\alpha$-smooth muscle actin ( $\alpha$-SMA) and Masson's trichrome (TRI) in sham controls and at 15 weeks post-radiation (RT) \pm one dose of monoclonal antibody (mAb) 2A11 24 hours post-RT. A: Diagram of experimental protocol: Mice were exposed to 15-Gy RT, then 24 hours later were injected with one dose of mAb $2 \mathrm{~A} 11$ or phosphate-buffered saline (PBS). At 15 weeks later, lung histology was evaluated by immunostaining for $\alpha$-SMA to identify smooth muscle cells and myofibroblasts and by TRI histochemical staining for collagen. B-D: $\alpha$-SMA immunostaining. B: Sham controls had $\alpha$-SMA ${ }^{+}$immunostaining only in smooth muscle of airways (Aw) and vasculature (v). C: At 15 weeks post-RT, RT + PBS mice demonstrated many $\alpha$-SMA ${ }^{+}$ myofibroblasts scattered throughout alveoli (dashed arrows), as well as airway and vascular smooth muscle associated with airways and vasculature. D: In the $\mathrm{RT}+\mathrm{mAb} 2 \mathrm{~A} 11$ mice, few $\alpha$-SMA ${ }^{+}$myofibroblasts are detected in the alveolar interstitium (dashed arrows). Most $\alpha$-SMA ${ }^{+}$cells are normal smooth muscle cells in airways and blood vessels (solid arrows). E and F: TRI staining. E: In sham controls, TRI staining is present only in supporting structures of Aw and blood vessels (v). F: In RT + PBS lung, trichrome staining is present in alveolar interstitium (dashed arrows) and in numerous fibroblasts bridging alveoli (dashed arrow with asterisk). G: After RT + mAb 2 A11 treatment, TRI is reduced in alveoli. Scale bars $=50 \mu \mathrm{m}(\mathbf{B}-\mathbf{G})$. IP, intraperitoneally.

dense fibrosis in 3 of 11 mice (Figure 4, C and D). Thus, $27 \%$ of RT + PBS mice developed one or two small solid nodules of $\mathrm{TRI}^{+} / \mathrm{Col}-1^{+}$fibrosis in distal lung, approximately 50 to $150 \mu \mathrm{m}$ in diameter, that obscured alveolar architecture (Figure 4, C and D). None of the RT $+\mathrm{mAb}$ 2A11 mice had any solid foci (data not shown).

Given the validation of TRI as a specific marker of collagen in lung (secreted by synthetic fibroblasts), we performed quantitative ImageJ analysis for both $\alpha$-SMA and TRI in close serial sections to define the extent of fibrosis in the various groups, focusing on the distal alveolar region in which collagen is not normally observed. As shown in Figure 4E, there was 15 -fold more $\alpha$-SMA and 5 -fold more TRI in $\mathrm{RT}+\mathrm{PBS}$ mice compared with either sham + PBS baseline mice or $\mathrm{RT}+\mathrm{mAb} 2 \mathrm{~A} 11$ controls. These data indicate that a single mAb $2 \mathrm{~A} 11$ injection at 24 hours post-RT reduces numbers of $\alpha-\mathrm{SMA}^{+}$myofibroblasts and collagen deposition 15 weeks later in the distal alveoli of RT-exposed mice.

To address the hypothesis that GRP might promote RTP and/or RTPF by activating macrophages, ${ }^{15}$ we performed
CD68 immunostaining of lung sections from RT + PBS and $\mathrm{RT}+\mathrm{mAb} 2 \mathrm{~A} 11$ mice (Supplemental Figure S2). Only rare macrophages were detected in sham controls or in lungs at 6 or 24 hours post-RT ( $n=4$ per time point). There was no significant difference in numbers of $\mathrm{CD} 68^{+}$macrophages in lung at 15 weeks post-RT (quantified over all lobes on the entire slide as number of $\mathrm{CD}^{+} 8^{+}$cells per $\mathrm{mm}^{2}$ lung tissue) between $\mathrm{RT}+\mathrm{PBS}$ and $\mathrm{RT}+\mathrm{mAb} 2 \mathrm{~A} 11$ mice (Supplemental Figure S2A). Only rare macrophages were detected in sham controls or in lungs at 6 or 24 hours postRT ( $n=4$ per time point) (Supplemental Figure S2B). However, there was a distinct morphology between the two groups: RT + PBS mice had intensely $\mathrm{CD}^{+} 8^{+}$cells scattered throughout the alveoli of most of the slides (Supplemental Figure S2C). In contrast, in RT $+\mathrm{mAb}$ 2A11 mice, cells were less intensely $\mathrm{CD}^{+} 8^{+}$and tended to be clustered in niches, often in the subpleural region (Supplemental Figure S2D). The significance of differences in macrophage morphology and location is unclear from the present study. 

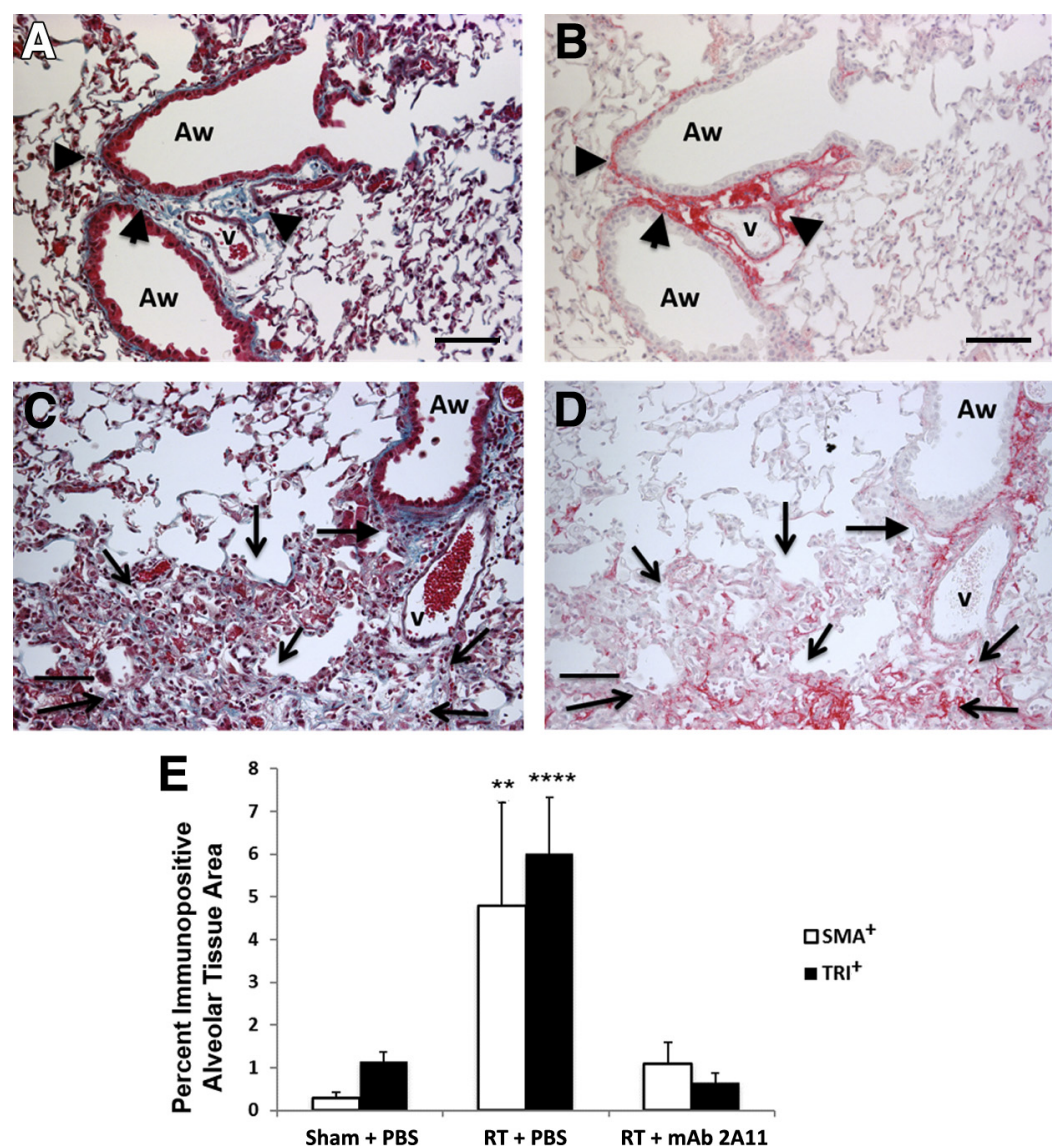

口SMA $^{+}$

- $\mathrm{TRI}^{+}$
Figure 4 Comparison of staining of mouse lung 15 weeks post-RT for Masson trichrome (TRI) versus collagenI (Col-I). A-D: Immediately adjacent lung sections from C57L/J mice 15 weeks post-RT (A and $\mathbf{B}$ versus $\mathbf{C}$ and $\mathbf{D}$ ) were stained to confirm that areas positive for TRI ( $A$ and C) also stained for Col-I (B and D). A and B: In one mouse, TRI histochemical staining surrounds bronchioles and associated blood vessels (arrowheads) (A), aligning with Col-I immunostaining (B). C and D: At 15 weeks post-RT (15 Gy), TRI (C) and Col-I (D) surround airways and blood vessels (arrowheads). A region of alveolar fibrosis (C; arrows) aligns with Col-I in D. Arrowheads indicate normal TRI and Col-I. E: ImageJ quantification results for alveolar area percent positive for SMA and TRI in Sham + PBS, RT + PBS, and RT + 2 A11 groups. Graphs represent percent positive SMA or TRI in alveolar tissue. Data are from quantification in Sham + PBS, RT + PBS, and RT + $2 A 11$ groups. Data are from a representative experiment. $n=4$ sham + PBS, 15-Gy RT + PBS, and RT + mAb $2 \mathrm{~A} 11$ (E). ${ }^{* * P}<0.01,{ }^{* * * * P}<0.0001$ versus $\mathrm{RT}+\mathrm{mAb} 2 \mathrm{~A} 11$ or sham controls. Scale bars $=50 \mu \mathrm{m}(\mathbf{A}-\mathbf{D})$.

\section{Multiplex, Proteomics, and Phosphoproteomics Analysis}

We first performed multiplex analysis for inflammatory cytokines on lung tissue harvested from two separate cohorts with three to eight mice per group at 24 hours post$\mathrm{RT}+\mathrm{PBS}$ versus post-RT + mAb 2A11 to explore potential mechanistic pathways involved in early GRP responses. IL-10 was the only cytokine significantly elevated in both cohorts 24 hours post-RT (Figure 5), and mAb $2 \mathrm{~A} 11$ abrogated this increase. There were no differences in other measured cytokines between the treatment groups.

Peptide and phosphopeptide analysis was performed by the Duke Phosphoproteomics Core Laboratory, as previously described. ${ }^{11}$ These data were submitted into a public repository at University of California, San Diego (https:// massive.ucsd.edu/ProteoSAFe/static/massive.jsp; data set identifier: MSV000083012; registration required.) Our current analysis identified 4666 unique nondecoy peptides. Because of the early effects of mAb 2A11 on RTPF 15 weeks later, we focused on changes in proteomics or phosphoproteomics at 24 hours post-RT \pm mAb $2 \mathrm{~A} 11$. Few proteomic changes existed with radiation among the top 500 to 700 proteins, with only three unmodified proteins altered at 24 hours post-RT with fold change $>1.5$ and $P<0.05$ (Supplemental Table S1). There were also limited proteomic changes between $\mathrm{RT}+\mathrm{PBS}$ and $\mathrm{RT}+\mathrm{mAb}$ 2A11 (Supplemental Table S2).

By contrast, we observed significant alterations in protein phosphorylation, reflecting a broad effect of RT + PBS versus sham (Table 1) and $\mathrm{RT}+\mathrm{mAb} 2 \mathrm{~A} 11$ versus RT + PBS (Table 2). Of the 4666 unique peptides, 3995 phosphopeptides were identified, representing 1488 unique phosphoproteins. After data quality control and outlier screening, ${ }^{11} 2905$ phosphopeptides were validated. Data were processed with Rosetta Elucidator ED 6095 (Cyrus Biotechnology, Seattle, WA) to identify potential signaling pathways (Figure 6, B and D, and Supplemental Figures S3 and S4). Statistical analyses were performed to identify candidate differentially expressed phosphopeptides by using a one-tailed $t$-test: $\mathrm{RT}+\mathrm{PBS}$ versus sham and $\mathrm{RT}+\mathrm{mAb}$ $2 \mathrm{~A} 11$ versus $\mathrm{RT}+\mathrm{PBS}$. Average expression values were screened for $P<0.05$ and for fold change $\geq 1.5$-fold between treatment groups (Supplemental Tables S3 and S4). Hierarchical clustering was performed to identify signature patterns and to confirm clustering on the basis of the experimental condition (Figure 6, A and C). RT + PBS versus sham lungs had several individually altered phosphoproteins possibly relevant to injury, fibrosis, or homeostasis (Table 1): platelet-derived growth factor (PDGF) receptor- $\alpha$, serine/threonine-serine/threonine protein kinase D2 (Prkd2), and serine/threonine-protein kinase large 
tumor suppressor kinase 1 (serine/threonine-protein kinase, alias Lats). One phosphoprotein that is decreased with $\mathrm{RT}+\mathrm{PBS}$ versus sham is the death-associated protein kinase 2 (Table 1). In Table 2, comparing lungs from mice treated with $\mathrm{RT}+\mathrm{mAb} 2 \mathrm{~A} 11$ versus $\mathrm{RT}+\mathrm{PBS}$, we observed many individually altered phosphoproteins that could be protective, with homeostatic or antioxidant functions. The complete listings of altered phosphoproteins are provided in Supplemental Tables S3 and S4. These data indicate that, soon after RT exposure, there are significant changes in protein phosphorylation that can be shifted by mAb 2A11 treatment, supporting potential early mechanistic links in signaling pathways between GRP and RTPF.

\section{Discussion}

GRP is a well-characterized growth factor for fibroblasts, normal bronchial epithelial cells, and many carcinomas. ${ }^{16} \mathrm{It}$ also functions as a bronchoconstrictor or vasoconstrictor in some animal models, ${ }^{17}$ as a neuroregulatory factor in the gut and brain, ${ }^{18}$ and as an immunomodulatory peptide. ${ }^{19}$ Initially, we became interested in a potential role for GRP in fetal lung development because GRP in the lung is produced only by PNECs, with peak levels of GRP mRNA occurring at midgestation in human fetal lung. ${ }^{20} \mathrm{We}$ showed a role for GRP in cell proliferation and cell differentiation in mice in vivo and in baboon and human fetal lung in tissue culture. This body of work led to the question of why GRP ${ }^{+}$ PNECs are increased in lungs of infants dying with bronchopulmonary dysplasia (BPD). ${ }^{21}$ Subsequent investigations in infants and in baboon models of BPD demonstrated GRP secretion within days after birth, ${ }^{10,22}$ and BPD was abrogated by GRP blockade in baboon models. ${ }^{10,23}$ In both BPD models, GRP-blocking mAb 2A11 reduced interstitial cell proliferation and alveolar wall thickness.

The current study was designed to test the hypothesis that early GRP blockade might reduce RT-induced pulmonary interstitial fibrosis 3 months later. Even before most cytokines are induced, radiation triggers immediate GRP release, with peak detection at approximately 6 hours post-RT. PNECs, the source of GRP in lung, are $\mathrm{O}_{2}$-sensing cells that degranulate in response to oxidant stress. GRP secretion is blocked by mAb $2 \mathrm{~A} 11 .{ }^{24}$ The observation that a single dose of mAb $2 \mathrm{~A} 11$ given 24 hours post-RT can mitigate RTPF 15 weeks later is unexpected. The lower GRP detection in urine after mAb $2 \mathrm{~A} 11$ treatment was also unexpected. GRP could be degraded when bound to $\mathrm{mAb} 2 \mathrm{~A} 11$, or there could be accelerated GRP clearing in the liver and/or spleen after binding of the constant region of mAb $2 \mathrm{~A} 11$ to specific $\mathrm{IgG}$ receptors on the macrophage surface $(\mathrm{FcRg})$.

The potential human relevance of our data in mice would be an interesting area for future research. If early treatment with mAb 2A11 abrogates RTPF in nonhuman primates and/or humans, this could become clinically important for

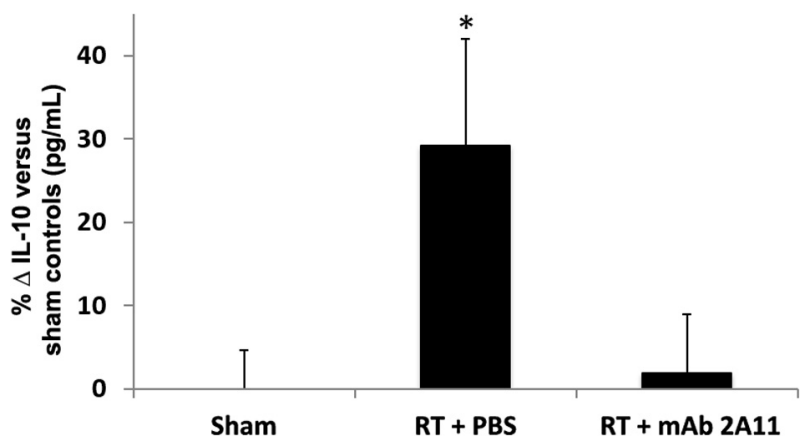

Figure 5 Multiplex analysis of inflammatory cytokines in mouse lung 24 hours post-radiation (RT) identifies elevated IL-10 levels that are abrogated by monoclonal antibody (mAb) $2 \mathrm{~A} 11$ treatment. $\mathrm{C} 57 \mathrm{~L} / \mathrm{J}$ mice were exposed to $15-G y$ thoracic $R T \pm$ a single intraperitoneal injection of $\mathrm{mAb} 2 \mathrm{~A} 11$ at approximately 0.1 hours post-RT. Lung tissues and bronchoalveolar lavage (BAL) fluid were investigated by multiplex analysis for 26 inflammatory cytokines (ProCartaPlex-I; Thermo Fisher Scientific, Waltham, MA). There were no significant differences in levels of any cytokine in BAL fluid. In lung, there was an overall $30 \%$ increase in IL-10 levels per lobe $(P<0.03)$ that was significantly reduced to baseline levels by mAb $2 \mathrm{~A} 11(P<0.035)$. Results are pooled data from two experiments that were normalized as percentage change from sham control values (mean of sham values is defined as zero). $n=11$ mice per group. ${ }^{*} P<0.05$ versus sham controls or to the RT + mAb 2A11 group. PBS, phosphate-buffered saline.

cancer patients to prevent later development of PF. Shortterm treatment with an anti-GRP mAb could also have implications for protecting large numbers of subjects after radiation disasters.

We did not observe any mortality in the $\mathrm{L} / \mathrm{J}$ mice used in the current study, including non-fibrosis-induced mortalities. In the pathogenesis of diverse chronic diseases, overlap in inflammatory and fibrotic pathways commonly occurs in diverse organ systems. We sought to identify a time point at which $\alpha$-SMA and/or trichrome staining was significantly increased before the mice became terminally ill to test our hypothesis that early treatment with GRP-blocking $\mathrm{mAb}$ 2A11 could delay or abrogate a profibrotic pathway. Our observations support this hypothesis, specifically the abrogation of $\alpha$-SMA ${ }^{+}$myofibroblasts that peaks over 17 -fold at 15 weeks. Thus, early treatment with GRP-blocking mAb could be clinically useful in abrogating or delaying early cellular mechanisms of fibrosis months later.

Previously, bystander effects of RT were described, mostly in the context of medium from irradiated cells transferring apoptosis to similarly cultured non-irradiated cells. ${ }^{25}$ Herein, we demonstrate that an endogenous peptide growth factor can mediate radiation injury and the development of RTPF, with altered profibrotic or antifibrotic pathways signaling pathways as soon as 24 hours post-RT. Moreover, a single downstream cytokine, IL-10, increased in mouse lung 24 hours post-RT and was abrogated by $\mathrm{mAb}$ 2A11. IL-10 has complex roles in regulating host responses, including profibrotic functions. ${ }^{26,27}$ This may be clinically relevant as IL-10 was found to be elevated in patients developing inflammatory radiation pneumonitis, ${ }^{28}$ although there was no correlation between levels of IL-10 and 
Table 1 Representative Lung Phosphoproteomics at 24 Hours Post-RT + PBS versus Sham + PBS

\begin{tabular}{|c|c|c|c|}
\hline Protein ID* & Protein description (abbreviation) & $\begin{array}{l}\text { Normal functions of proteins or } \\
\text { phosphoproteins }\end{array}$ & FC: RT/sham \\
\hline NP_083007.2 & Extended synaptotagmin-2 (Esyt2) & $\begin{array}{l}\text { Deficiency reduces response to oxidative } \\
\text { stress }\end{array}$ & 2.3 \\
\hline NP_035188.2 & PDGF receptor- $\alpha$ precursor (Pdgfra) & Promotes pulmonary fibrosis & 3.1 \\
\hline NP_082160.3 & Tensin 1 (Tns1, Hic5) & $\begin{array}{l}\text { Mediates TGF- } \beta \text {-induced EMT and } \\
\text { cell migration }\end{array}$ & 2.2 \\
\hline NP_001129543.1 & Lymphocyte-specific protein 1 (Lsp1) & Increased fibrosis in Lsp1-deficient mice & -2.6 \\
\hline NP_033212.1 & Transformer-2 protein homolog $\beta$ (Tra2b) & $\begin{array}{l}\text { Normally protects versus ischemia/reperfusion } \\
\text { injury }\end{array}$ & -2.9 \\
\hline
\end{tabular}

*Protein IDs are searchable at the National Center for Biotechnology Information, http://www.ncbi.nlm.nih.gov

EMT, epithelial to mesenchymal transitions; FC, fold change; ID, identification; LDL, low-density lipoprotein; PBS, phosphate-buffered saline; PDGF, plateletderived growth factor; RT, radiation; TGF- $\beta$, transforming growth factor- $\beta$.

RTPF. $^{3}$ The significance of IL-10 in the present study is unknown as a direct cause of RTPF but supports it as a mediator of RTP and a target of suppression by mAb $2 \mathrm{~A} 11$.

To explore potential mechanisms by which GRP might mediate RTPF, we leveraged analysis of proteomics/phosphoproteomics at 24 hours post-RT \pm mAb 2A11. Although the proteomic analysis did not identify significant differences between the sham + PBS and RT + PBS groups, it is possible that proteomic changes are not adequately measured at the 24-hour time point, which could reflect either a lack of protein translation or having missed translation that has already occurred. For instance, in strains of mice that are susceptible to RTPF, serum levels of IL-10, interferon- $\gamma$, and tumor necrosis factor- $\alpha$ were elevated at 6 hours, 12 hours, and 7 days post-RT; IL-10 levels at 7 days inversely correlated with later fibrosis, whereas high IL-17 levels protected against fibrosis. ${ }^{29}$ Interestingly, serum levels of IL-17 in control mice significantly correlated with postirradiation survival time. However, we did not observe similar changes in our model. Given that we sought to assess early responses to $\mathrm{RT} \pm \mathrm{mAb} 2 \mathrm{~A} 11$, our time points were limited in the present study. To better define patterns of proteomic changes, a more detailed post-RT time course would be helpful in future studies. The complexity of these responses over time, the numbers of cytokines, and the use of systems biology approaches are likely to require highthroughput analysis with rigorous statistical analyses to decipher the major pathways altered by mAb 2A11 in larger numbers of mice at multiple time points over the first week post-RT.

Interestingly, the most significant changes in phosphoproteomics were observed with $\mathrm{RT} \pm \mathrm{mAb} 2 \mathrm{~A} 11$ versus $\mathrm{RT} \pm$ PBS treatment at 24 hours post-RT. These data offer the greatest mechanistic insight into pathways regulated by $\mathrm{RT}$ and those responsive to mAb $2 \mathrm{~A} 11$. It has been known for decades that protein phosphorylation and dephosphorylation are key events regulating activation and deactivation of signaling proteins during signal transduction. ${ }^{30}$ Altered protein phosphorylation can be observed within seconds to minutes after receptor

Table 2 Representative Lung Phosphoproteomics at 24 Hours Post-RT + mAb 2 A11 versus RT + PBS

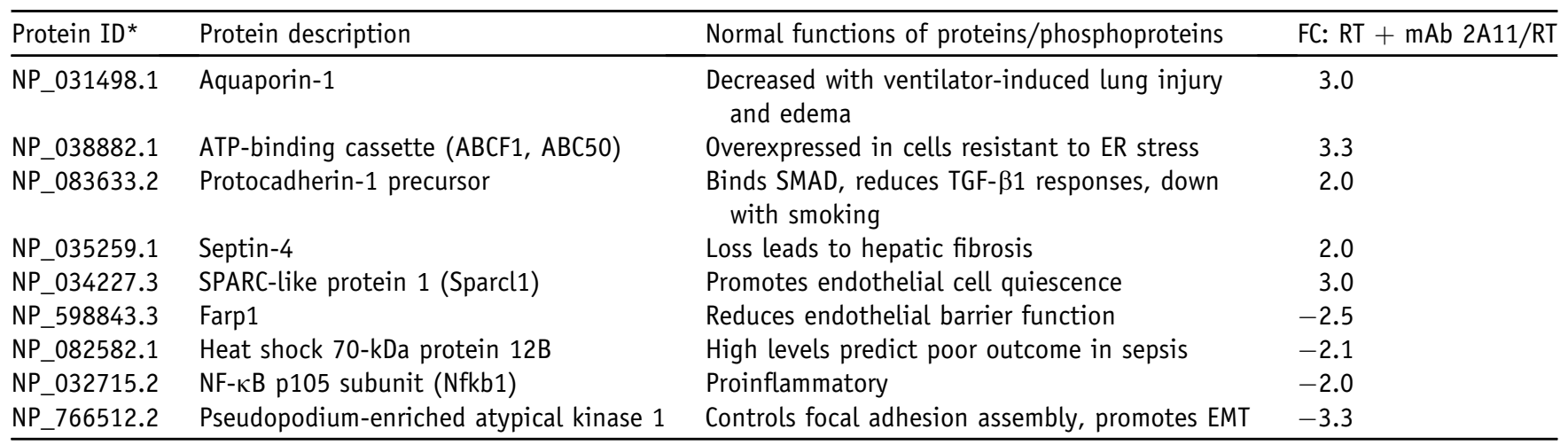

*Protein IDs are searchable at the National Center for Biotechnology Information, http://www.ncbi.nlm.nih.gov

EMT, epithelial to mesenchymal transitions; ER, endoplasmic reticulum; FC, fold change; ID, identification; mAb, monoclonal antibody; PBS, phosphatebuffered saline; RT, radiation; TGF- $\beta 1$, transforming growth factor- $\beta 1$. 

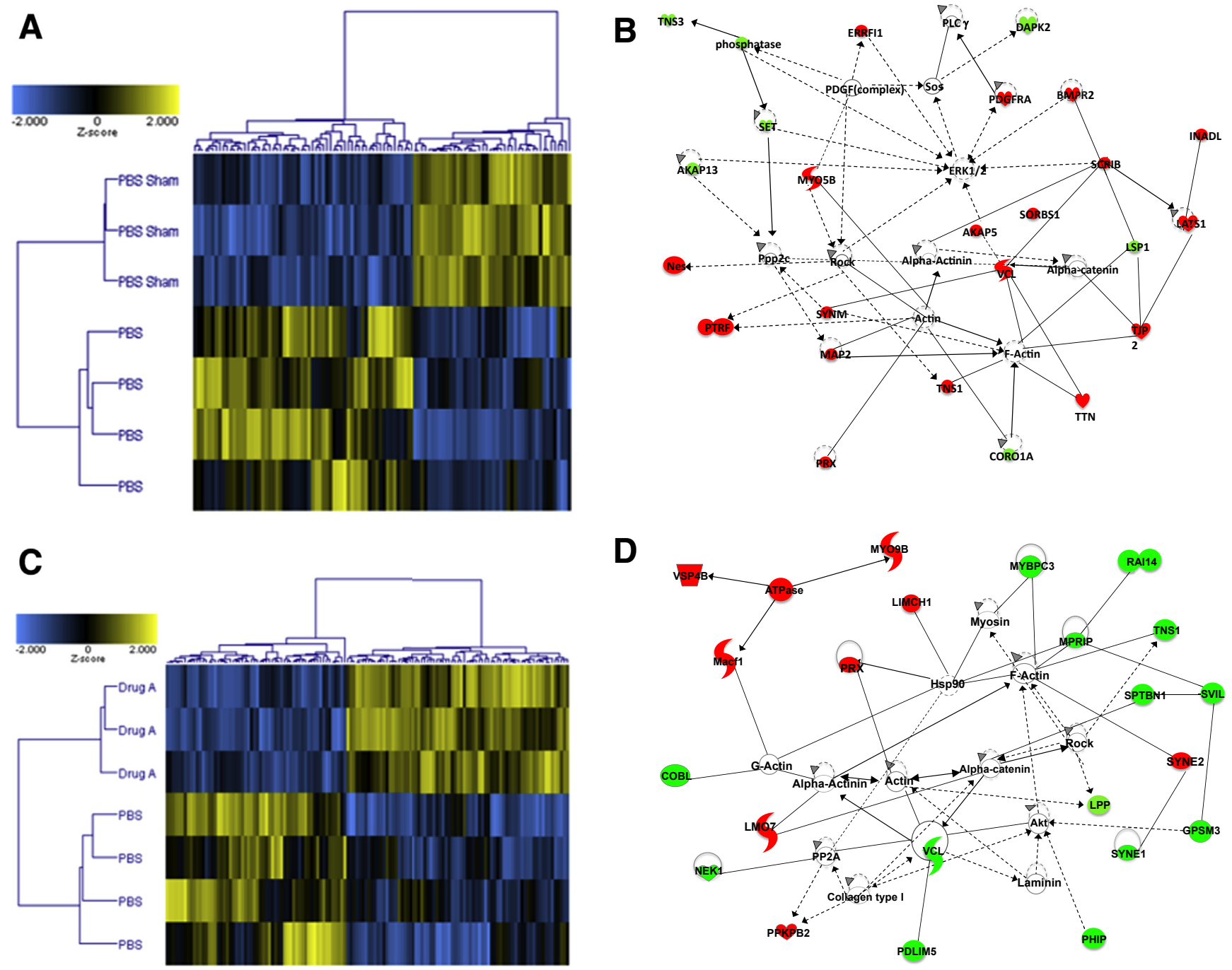

Figure 6 Overview of Ingenuity Pathway Analysis of mouse lung phosphoproteomics. A and B: Radiation (RT) + phosphate-buffered saline (PBS) versus sham (PBS sham). Top network 1: cellular assembly, organization, and function; and tissue development and maintenance. Proteins in red had increased phosphorylation in lung from RT + PBS versus shams, whereas phosphorylated proteins in green were decreased in RT + PBS versus sham. C and D: RT + monoclonal antibody (mAb) 2A11 (drug A) versus RT + PBS (PBS). Top network 1: cell morphology, organ morphology, and skeletal and muscular system development and function. Proteins in red had increased phosphorylation in RT + mAb 2A11 versus RT + PBS tissue. Proteins in green had decreased phosphorylation in RT + mAb 2 A11 versus RT + PBS tissue.

activation after an insult or injury. Thus, protein phosphorylation could be a more sensitive indicator of direct and indirect pathways triggered by GRP signaling. ${ }^{31}$ When we compared RT + PBS with sham + PBS phosphoproteomics (Supplemental Table S3), we observed increased PDGF receptor- $\alpha$ signaling, which can lead to matrixproducing fibroblast differentiation. ${ }^{32}$ This is likely to be an indirect activator of PDGF receptor- $\alpha$ because the signaling pathways triggered by PDGF and GRP are distinct. ${ }^{33}$ Conversely, reduced death-associated protein kinase 2 phosphorylation is probably indirectly profibrotic because deleting the death-associated protein kinase $2 \mathrm{ki}$ nase domain suppresses renal fibrosis by inhibiting epithelial to mesenchymal transitions (EMT) or transdifferentiation programs and emerging $\alpha$-SMA ${ }^{+}$ myofibroblasts. ${ }^{34}$ Comparing lungs from RT + mAb 2A11 with RT + PBS mice (Supplemental Table S4), different sets of phosphoproteins were identified. Increased ATPbinding cassette would likely be protective because ATPbinding cassette decreases sensitivity to endoplasmic reticulum stress agents. ${ }^{35}$ Protocadherin binds SMAD and reduces transforming growth factor- $\beta$ responses. ${ }^{36}$ Also, protocadherin is decreased with smoking ${ }^{37}$ which is a risk factor for $\mathrm{PF}^{38}$ Conversely, lung phosphoproteins, decreased at 24 hours post-RT + mAb 2 A11 versus RT + PBS, could protect against RTPF. For example, NF$\kappa \mathrm{B} 1$ is critical for the pathogenesis of many chronic lung diseases, including BPD, ${ }^{39}$ and decreased NF- $\mathrm{BB} 1$ phosphorylation could be protective. This could be directly linked to GRP signaling because gene expression for the 
lower-affinity neuromedin $\mathrm{B}$ receptor in the uterus is closely aligned with the $\mathrm{NF \kappa B}$ transactivator reticuloendotheliosis viral oncogene homolog A (RelA, alias p65) DNA-binding activity. ${ }^{40}$ In a rat model of RTPF, DNA binding of NF- $\kappa \mathrm{B}$ is continuously activated postRT. ${ }^{41}$ Finally, pseudopodium-enriched atypical kinase 1 (Peak1) is required for regulation of cell migration and focal adhesion. ${ }^{42}$ Dynamic phosphorylation of Peak1 could be an indirect effect of GRP signaling regulating transforming growth factor- $\beta$-induced EMT via its interaction with or regulation of other genes.

To understand how these changes could be systemically integrated, we performed a computerized analysis of altered signaling pathways (Figure 6, Supplemental Figures S3 and S4, and Supplemental Tables S5 and S6). Cellular GRP signaling begins with ligand binding and activation of the high-affinity GRP receptor and/or lower-affinity neuromedin B receptor. Signaling at these receptors can be transduced via multiple pathways, including focal adhesion kinase, protein kinase $\mathrm{C}$, and $\mathrm{p} 38$ mitogen-activated protein kinase, but not protein kinase $\mathrm{A}^{43}$ Both the high-affinity GRP receptor and lower-affinity neuromedin B receptor are G-protein-coupled receptors known to cross activate receptor tyrosine kinases, including PDGF receptors and focal adhesion kinase, activating matrix metalloproteinases and releasing ligands for receptor tyrosine kinases from the cell surface. ${ }^{44}$ Because we observe several phosphoprotein changes, we propose that several of these, especially focal adhesion kinase signaling [identified in the Ingenuity Pathway Analysis (Qiagen Bioinformatics, Redwood City, CA)] and NF- $\kappa$ B activation, are likely to be direct effects of high-affinity GRP receptor and/or lower-affinity neuromedin B receptor activation. Deficient protein kinase A signaling in RT + PBS versus sham + PBS lung could promote acute lung injury during early radiation pneumonitis and/or RTPF ${ }^{45}$ because protein kinase A activation can protect against oxidative stress-induced lung injury and fibrosis. ${ }^{46}$ In contrast, we observed distinct changes in phosphoproteins and signaling in $\mathrm{RT}+\mathrm{mAb} 2 \mathrm{~A} 11$ versus RT + PBS lungs. mAb $2 \mathrm{~A} 11$ treatment was strongly associated with decreased actin-cytoskeletal signaling, especially via focal adhesion kinase, which could lead to cell flattening, decreased cell proliferation, and reduced migration of myofibroblasts or other mesenchymal or epithelial progenitor cells. These data support the paradigm that, as early as 24 hours post-RT, several phosphorylated profibrotic signaling pathways are mitigated by treatment with GRP blockade, protecting lung from endoplasmic reticulum stress and ultimately fibrotic responses.

In conclusion, we identified an early GRP-mediated mechanism leading to RTPF. Elevated urine levels of GRP could be a clinically relevant mechanistic biomarker to predict which mouse strains or human subjects are at highest risk for developing RTPF. Furthermore, a single early dose of neutralizing GRP mAb blocked RTPF. This suggests that GRP could have clinical usefulness not only in identifying individuals at risk for RTPF. GRP blockade could potentially prevent, arrest, or reverse incipient RTPF in populations such as cancer patients treated with RT or prevent RTPF in large populations exposed to nuclear accidents.

\section{Acknowledgments}

We thank Dr. Mark Dewhirst for critical review of the manuscript and Steve Conlon for expert assistance with photomicrography.

\section{Supplemental Data}

Supplemental material for this article can be found at http://doi.org/10.1016/j.ajpath.2019.01.017.

\section{References}

1. Carver JR, Shapiro CL, Ng A, Jacobs L, Schwartz C, Virgo KS, Hagerty KL, Somerfield MR, Vaughn DJ; ASCO Cancer Survivorship Expert Panel: American Society of Clinical Oncology clinical evidence review on the ongoing care of adult cancer survivors: cardiac and pulmonary late effects. J Clin Oncol 2007, 25:3991-4008

2. Marks LB, Bentzen SM, Deasy JO, Kong FM, Bradley JD, Vogelius IS, El Naqa I, Hubbs JL, Lebesque JV, Timmerman RD, Martel MK, Jackson A: Radiation dose-volume effects in the lung. Int J Radiat Oncol Biol Phys 2010, 76:S70-S76

3. Mazeron R, Etienne-Mastroianni B, Perol D, Arpin D, Vincent M, Falchero L, Martel-Lafay I, Carrie C, Claude L: Predictive factors of late radiation fibrosis: a prospective study in non-small cell lung cancer. Int J Radiat Oncol Biol Phys 2010, 77:38-43

4. Zhou S, Nissao E, Jackson IL, Leong W, Dancy L, Cuttitta F, Vujaskovic Z, Sunday ME: Radiation-induced lung injury is mitigated by blockade of gastrin-releasing peptide. Am J Pathol 2013, 182:1248-1254

5. Jackson IL, Xu P, Hadley C, Katz BP, McGurk R, Down JD, Vujaskovic Z: A preclinical rodent model of radiation-induced lung injury for medical countermeasure screening in accordance with the FDA animal rule. Health Phys 2012, 103:463-473

6. Jackson IL, Vujaskovic Z, Down JD: Revisiting strain-related differences in radiation sensitivity of the mouse lung: recognizing and avoiding the confounding effects of pleural effusions. Radiat Res 2010, $173: 10-20$

7. Dabjan MB, Buck CM, Jackson IL, Vujaskovic Z, Marples B, Down JD: A survey of changing trends in modelling radiation lung injury in mice: bringing out the good, the bad, and the uncertain. Lab Invest 2016, 96:936-949

8. Committee for the Update of the Guide for the Care and Use of Laboratory Animals; National Research Council: Guide for the Care and Use of Laboratory Animals: Eighth Edition. Washington, DC, National Academies Press, 2011

9. McGurk R, Hadley C, Jackson IL, Vujaskovic Z: Development and dosimetry of a small animal lung irradiation platform. Health Phys 2012, 103:454-462

10. Sunday ME, Yoder BA, Cuttitta F, Haley KJ, Emanuel RL: Bombesinlike peptide mediates lung injury in a baboon model of bronchopulmonary dysplasia. J Clin Invest 1998, 102:584-594

11. Richardson BM, Soderblom EJ, Thompson JW, Moseley MA: Automated, reproducible, titania-based phosphopeptide enrichment strategy for label-free quantitative phosphoproteomics. J Biomol Tech 2013, $24: 8-16$

12. Polak JM, Becker KL, Cutz E, Gail DB, Goniakowska-Witalinska L, Gosney JR, Lauweryns JM, Linnoila I, McDowell EM, Miller YE, 
Scheuermann DW, Springall DR, Sunday ME, Zaccone G: Lung endocrine cell markers, peptides, and amines. Anat Rec 1993, 236: 169-171

13. Phan SH: Genesis of the myofibroblast in lung injury and fibrosis. Proc Am Thorac Soc 2012, 9:148-152

14. Goldfine SM, Pena M, Magid NM, Liu SK, Borer JS: Myocardial collagen in cardiac hypertrophy resulting from chronic aortic regurgitation. Am J Ther 1998, 5:139-146

15. Shirey KA, Sunday ME, Lai W, Patel MC, Blanco JCG, Cuttitta F, Vogel SN: Novel role of gastrin releasing peptide-mediated signaling in the host response to influenza infection. Mucosal Immunol 2019, 12:223-231

16. Majumdar ID, Weber HC: Biology of mammalian bombesin-like peptides and their receptors. Curr Opin Endocrinol Diabetes Obes 2011, 18:68-74

17. Lach E, Haddad EB, Gies JP: Contractile effect of bombesin on guinea pig lung in vitro: involvement of gastrin-releasing peptide-preferring receptors. Am J Physiol 1993, 264:L80-L86

18. Martinez V, Tache Y: Bombesin and the brain-gut axis. Peptides 2000, $21: 1617-1625$

19. Kim MK, Park HJ, Kim Y, Kim HJ, Bae SK, Bae MK: Gastrinreleasing peptide induces monocyte adhesion to vascular endothelium by upregulating endothelial adhesion molecules. Biochem Biophys Res Commun 2017, 485:542-549

20. Spindel ER, Sunday ME, Hofler H, Wolfe HJ, Habener JF, Chin WW: Transient elevation of messenger RNA encoding gastrin-releasing peptide, a putative pulmonary growth factor in human fetal lung. $\mathbf{J}$ Clin Invest 1987, 80:1172-1179

21. Johnson DE, Kulik TJ, Lock JE, Elde RP, Thompson TR: Bombesin-, calcitonin-, and serotonin-immunoreactive pulmonary neuroendocrine cells in acute and chronic neonatal lung disease. Pediatr Pulmonol 1985, 1:S13-S20

22. Cullen A, Van Marter LJ, Allred EN, Moore M, Parad RB, Sunday ME: Urine bombesin-like peptide elevation precedes clinical evidence of bronchopulmonary dysplasia. Am J Respir Crit Care Med 2002, 165:1093-1097

23. Subramaniam M, Bausch C, Twomey A, Andreeva S, Yoder BA, Chang L, Crapo JD, Pierce RA, Cuttitta F, Sunday ME: Bombesin-like peptides modulate alveolarization and angiogenesis in bronchopulmonary dysplasia. Am J Respir Crit Care Med 2007, 176:902-912

24. Chang LY, Subramaniam M, Yoder BA, Day BJ, Ellison MC, Sunday ME, Crapo JD: A catalytic antioxidant attenuates alveolar structural remodeling in bronchopulmonary dysplasia. Am J Respir Crit Care Med 2003, 167:57-64

25. Mothersill C, Seymour CB: Radiation-induced bystander effects: implications for cancer. Nat Rev Cancer 2004, 4:158-164

26. Re SL, Giordano G, Yakoub Y, Devosse R, Uwambayinema F, Couillin I, Ryffel B, Marbaix E, Lison D, Huaux F: Uncoupling between inflammatory and fibrotic responses to silica: evidence from MyD88 knockout mice. PLoS One 2014, 9:e99383

27. Smoktunowicz N, Alexander RE, Franklin L, Williams AE, Holman B, Mercer PF, Jarai G, Scotton CJ, Chambers RC: The anti-fibrotic effect of inhibition of TGFbeta-ALK5 signalling in experimental pulmonary fibrosis in mice is attenuated in the presence of concurrent gammaherpesvirus infection. Dis Model Mech 2015, 8:1129-1139

28. Arpin D, Perol D, Blay JY, Falchero L, Claude L, Vuillermoz-Blas S, Martel-Lafay I, Ginestet C, Alberti L, Nosov D, EtienneMastroianni B, Cottin V, Perol M, Guerin JC, Cordier JF, Carrie C: Early variations of circulating interleukin- 6 and interleukin-10 levels during thoracic radiotherapy are predictive for radiation pneumonitis. J Clin Oncol 2005, 23:8748-8756

29. Paun A, Kunwar A, Haston CK: Acute adaptive immune response correlates with late radiation-induced pulmonary fibrosis in mice. Radiat Oncol 2015, 10:45

30. Karin M, Hunter T: Transcriptional control by protein phosphorylation: signal transmission from the cell surface to the nucleus. Curr Biol 1995, 5:747-757
31. Olsen JV, Blagoev B, Gnad F, Macek B, Kumar C, Mortensen P, Mann M: Global, in vivo, and site-specific phosphorylation dynamics in signaling networks. Cell 2006, 127:635-648

32. Green J, Endale M, Auer H, Perl AK: Diversity of interstitial lung fibroblasts is regulated by platelet-derived growth factor receptor alpha kinase activity. Am J Respir Cell Mol Biol 2016, 54:532-545

33. Blakeley DM, Corps AN, Brown KD: Bombesin and platelet-derived growth factor stimulate formation of inositol phosphates and $\mathrm{Ca} 2+$ mobilization in Swiss 3 T3 cells by different mechanisms. Biochem J 1989, 258:177-185

34. Yukawa K, Kishino M, Hoshino K, Shirasawa N, Kimura A, Tsubota Y, Owada-Makabe K, Bai T, Tanaka T, Ueyama T, Ichinose M, Takeda K, Akira S, Maeda M: The kinase domain of death-associated protein kinase is inhibitory for tubulointerstitial fibrosis in chronic obstructive nephropathy. Int J Mol Med 2005, 15:73-78

35. Yu Y, Zhang Y, Zhu Z, Berger SA: ABC50 modulates sensitivity of HL60 leukemic cells to endoplasmic reticulum (ER) stress-induced cell death. Biochem Pharmacol 2011, 81:488-497

36. Faura Tellez G, Vandepoele K, Brouwer U, Koning H, Elderman RM, Hackett TL, Willemse BW, Holloway J, Van Roy F, Koppelman GH, Nawijn MC: Protocadherin-1 binds to SMAD3 and suppresses TGFbeta1-induced gene transcription. Am J Physiol Lung Cell Mol Physiol 2015, 309:L725-L735

37. Koning H, van Oosterhout AJ, Brouwer U, den Boef LE, Gras R, Reinders-Luinge M, Brandsma CA, van der Toorn M, Hylkema MN, Willemse BW, Sayers I, Koppelman GH, Nawijn MC: Mouse protocadherin-1 gene expression is regulated by cigarette smoke exposure in vivo. PLoS One 2014, 9:e98197

38. Steele MP, Schwartz DA: Molecular mechanisms in progressive idiopathic pulmonary fibrosis. Annu Rev Med 2013, 64:265-276

39. Ali S, Hirschfeld AF, Mayer ML, Fortuno ES 3rd, Corbett N, Kaplan M, Wang S, Schneiderman J, Fjell CD, Yan J, Akhabir L, Aminuddin F, Marr N, Lacaze-Masmonteil T, Hegele RG, Becker A, Chan-Yeung M, Hancock RE, Kollmann TR, Daley D, Sandford AJ, Lavoie PM, Turvey SE: Functional genetic variation in NFKBIA and susceptibility to childhood asthma, bronchiolitis, and bronchopulmonary dysplasia. J Immunol 2013, 190:3949-3958

40. Zhang WS, Xie QS, Wu XH, Liang QH: Neuromedin B and its receptor induce labor onset and are associated with the RELA (NFKB P65)/IL6 pathway in pregnant mice. Biol Reprod 2011, 84: $113-117$

41. Haase MG, Klawitter A, Geyer P, Alheit H, Baumann M, Kriegel TM, Kasper M, Baretton GB: Sustained elevation of NF-kappaB DNA binding activity in radiation-induced lung damage in rats. Int J Radiat Biol 2003, 79:863-877

42. Bristow JM, Reno TA, Jo M, Gonias SL, Klemke RL: Dynamic phosphorylation of tyrosine 665 in pseudopodium-enriched atypical kinase 1 (PEAK1) is essential for the regulation of cell migration and focal adhesion turnover. J Biol Chem 2013, 288:123-131

43. Ramos-Alvarez I, Moreno P, Mantey SA, Nakamura T, NucheBerenguer B, Moody TW, Coy DH, Jensen RT: Insights into bombesin receptors and ligands: highlighting recent advances. Peptides 2015, 72 : $128-144$

44. Jensen RT, Battey JF, Spindel ER, Benya RV: International Union of Pharmacology: LXVIII: mammalian bombesin receptors: nomenclature, distribution, pharmacology, signaling, and functions in normal and disease states. Pharmacol Rev 2008, 60:1-42

45. Uzdensky A, Berezhnaya E, Khaitin A, Kovaleva V, Komandirov M, Neginskaya M, Rudkovskii M, Sharifulina S: Protection of the crayfish mechanoreceptor neuron and glial cells from photooxidative injury by modulators of diverse signal transduction pathways. Mol Neurobiol 2015, 52:811-825

46. Schlegel N, Waschke J: cAMP with other signaling cues converges on Rac1 to stabilize the endothelial barrier: a signaling pathway compromised in inflammation. Cell Tissue Res 2014, 355:587-596 